\title{
HISTÓRIA E MEMÓRIA DO ENSINO DE FÍSICA NO BRASIL: A FACULDADE DE MEDICINA DE SÃO PAULO (1913-1943)
}

\section{History and memory of physics teaching in Brazil: the Faculty of Medicine of São Paulo (1913-1943)}

\author{
Roberto Bovo Nicioli Junior ${ }^{1 \dagger}$ • Cristiano Mattos ${ }^{2}$
}

\begin{abstract}
Resumo: Este trabalho apresenta um recorte histórico do ensino de Física na Faculdade de Medicina de São Paulo no período de 1913 a 1943. Vimos que o curso superior de Física foi essencial no remodelamento curricular da Física secundária. Destacamos a seleção cultural escolar por meio dos livros didáticos, apontando para aqueles que influenciaram e guiaram as mudanças curriculares da instituição, cujo enfoque curricular, no ensino de Física, foi criado em virtude de uma necessidade social. Mergulhamos nas práticas escolares por meio das relações microscópicas entre o que se estudava e que encontramos materializado nas avaliações do conteúdo de Física. Dessa forma, expusemos tradições pedagógicas, procedimentos e condutas sobre o cotidiano escolar da instituição que visavam aprimorar o ensino de Física. Assim, as questões e exercícios das provas analisadas, foram necessidades pedagógicas criadas dentro e para a escola, que não são constantes e uniformes, uma vez que dependem da sociedade, do público escolar e das matérias.
\end{abstract}

Palavras-chave: Livro didático. Ensino de Física. Prática de ensino. Ensino Superior.

Abstract: In this work we present a historical approach to the Physics teaching at the Faculty of Medicine of São Paulo from 1913 to 1943. We observed that college Physics was essential to remodel secondary Physics curriculum. We pointed out the school's cultural selection through textbooks pointing to those that influenced and guided the institution's curricular changes, whose curricular focus, in Physics teaching, was created to deal with a social need. We went through the school practices focusing on microscopic relationships in the content studied and what we found materialized in the Physics content evaluations. Thus, we exposed pedagogic traditions, procedures and practices about the daily study of the institution that was intended to improve Physics teaching. Then, the subjects and exercises, of the analyzed written evaluations, were pedagogic needs created inside and for the school. These are not constant and uniform, once they depend on the society, and the school community and neither are the contents.

Keywords: Textbook. Physics teaching. Teaching practice. Higher education.

\footnotetext{
${ }^{1}$ Programa de Pós-Graduação Interunidades em Ensino de Ciências, Universidade de São Paulo (USP), São Paulo, SP, Brasil. ${ }^{\dagger}$ In memoriam.

${ }^{2}$ Instituto de Física, USP. Rua do Matão, Travessa R, no 187, Cidade Universitária. São Paulo, SP, Brasil.

05.508-090.mattos@if.usp.br
} 
Nicioli Junior, R. B.; Mattos, C.

\section{Introdução}

A grande maioria dos trabalhos sobre a história do ensino de Física no Brasil produzidos nos últimos anos remonta à década de 1950, já que inovações educacionais iniciaram-se nessa época. Nardi (2005), por meio de entrevistas com os principais pesquisadores da área em ensino de Ciências, mostra que, nesse período, além da mudança no enfoque educacional científico, houve também o início da pesquisa em ensino de Ciências. As conclusões de Nardi (2005) apontam que essa mudança ocorre

[...] a partir de 1946 com a instalação do IBECC, quando essas instituições nacionais tomaram a liderança no desenvolvimento de materiais didáticos na área de ensino de ciências. A instalação do IBECC proporcionou a implantação de projetos que se iniciaram com o apoio a atividades escolares como feiras, museus e clubes de ciência, pesquisa e treinamento de professores. (NARDI, 2005, p. 67)

Posteriormente a esse período, o ensino em Ciências sofreu mudanças curriculares expressivas, passando a incorporar projetos estrangeiros, além de criar projetos de ensino nacionais, políticas de livros didáticos etc. (BARRA; LORENZ, 1986; KRASILCHIK, 1980; CARVALHO; VANUCCHI, 1996; GASPAR, 2004). Além disso, a pesquisa em ensino ganhou grande espaço, surgindo, a partir da década de 1970, grupos de pesquisa, simpósios e encontros de ensino de Ciências (ALMEIDA JUNIOR, 1979, 1980; VILLANI 1981, 1982; MOREIRA, 1977; RODRIGUES; HAMBURGER, 1993). Sobre os livros didáticos, Freitag, Motta e Costa (1989) e Oliveira (1984) destacam que sua história, a partir de 1930, não passa de uma sequência de decretos, leis e medidas, sendo a história desse período fortemente entrelaçada com as políticas públicas.

Com inúmeros trabalhos que exploram o ensino e a pesquisa em Ciências a partir da segunda metade do século XX, podemos traçar e compreender as intenções e transformações ocorridas até os dias de hoje. Porém, podemos indagar: anteriormente, ao final da década de 1940, como foi construída a história do ensino de Física? Para quais direções as pesquisas acadêmicas sobre esse período apontam? Como os livros didáticos se encaixavam no ensino de Física? Existia algum enfoque curricular nessa época? Se havia, ocorreu alguma mudança?

Nos poucos trabalhos já publicados, podemos responder parcialmente essas perguntas. Nos trabalhos de Haidar (1972) e Piletti (1987), que discorrem sobre o ensino secundário no império, encontramos alguns dados e verificamos que se estudava pouca ciência naquela época. Devido ao forte enfoque humanístico, as disciplinas científicas eram praticamente excluídas do currículo ${ }^{3}$. Um dado sobre o ensino de Física do império é que, mesmo o Colégio Pedro II sendo criado para ser uma referência educacional à sua época, acabou sofrendo a

\footnotetext{
${ }^{3}$ Essa exclusividade das disciplinas humanísticas era imposta pelo sistema de admissão ao Ensino Superior no Brasil, chamado preparatório. Esses preparatórios eram os certificados exigidos para o ingresso no Ensino Superior, sendo composto por disciplinas de caráter humanístico (NICIOLI JUNIOR; MATTOS, 2007a).
} 
forte influência do caráter humanístico. Apesar de possuir um currículo francês, baseado nas principais inovações científicas, poucas inscrições eram realizadas na disciplina de Física (NICIOLI JUNIOR; MATTOS 2007b).

Durante o século XIX, os livros didáticos eram predominantemente europeus, sobretudo franceses. Esses livros entraram no sistema de ensino brasileiro por meio dos programas curriculares do Colégio Pedro II, criado em 1838, que, além de organizarem o currículo nacional, sugeriam livros didáticos europeus para serem adotados (LORENZ, 1986; BARRA; LORENZ, 1986). Uma análise detalhada do conteúdo desses livros mostrou que suas abordagens ao longo do século XIX mudaram de uma simples descrição de conceitos de Física para uma abordagem demonstrativa-experimental, na qual eram deduzidas as equações a partir de experimentos (NICIOLI JUNIOR; MATTOS, 2007c). No início do século XX, livros de outras nacionalidades passam a fazer parte do cenário educacional brasileiro. Por exemplo, a Escola Politécnica de São Paulo ${ }^{4}$ passa a adotar livros didáticos norte-americanos, que possuíam características diferentes dos livros europeus, destacando-se, sobretudo, pelo seu conteúdo algebrizado. Livros didáticos de autores brasileiros começaram a ser publicados, porém muitos deles se tratavam de meras traduções de obras estrangeiras (NICIOLI JUNIOR; MATTOS 2008a).

Apesar de serem referência, os livros didáticos expressavam, no máximo, os conteúdos que poderiam ser trabalhados, sem a certeza de que foram realmente estudados. Algumas pesquisas apontam para a necessidade da análise do cotidiano escolar e sobre o conhecimento nele produzido, que, segundo Hamilton (1992), chama-se de o campo da bistória da educação escolar ou história da escolarização. Juliá (2001), por outro lado, salienta que devemos explorar a "caixa-preta" da escola e, para isso, temos de levar em consideração as práticas cotidianas sobre o funcionamento interno da escola. Deste ponto de vista, deveríamos recusar uma visão essencialmente externalista, na qual as histórias do meio escolar se fundamentam em textos legais. Deveríamos explorar mais as organizações internas da escola e o que Juliá (2001) define como cultura escolar, conceito ligado a diversas variáveis:

[...] poder-se-ia descrever a cultura escolar como um conjunto de normas que definem um conhecimento a ensinar e condutas a inculcar, e um conjunto de práticas que permitem a transmissão desses conhecimentos e a incorporação desses comportamentos; normas e práticas coordenadas a finalidades que podem variar segundo as épocas (finalidades religiosas, sócio-políticas ou simplesmente de socialização). Normas e práticas não podem ser analisadas sem se levar em conta o corpo

\footnotetext{
${ }^{4}$ A Escola Polítécnica de São Paulo, criada em 1893, foi anexada à Universidade de São Paulo em 1934, com sua criação. Até o ano de 1931, o ensino de Física de nível Médio estava nos três primeiros anos introdutórios dos cursos de engenharia, ou seja, no Superior. Com a Reforma Francisco Campos, em 1931, o conteúdo de nível Médio passa a fazer parte do Ensino Complementar (Ensino Médio atual), que era dividido em três cursos: $1^{\circ}$ curso - jurídico, $2^{\circ}$ curso - medicina, odontologia e farmácia, e $3^{\circ}$ curso - arquitetura e engenharia. Até as pesquisas atuais, sabemos que a Física estava nos cursos de engenharia e medicina (NICIOLI JUNIOR; MATTOS, 2008b).
} 
Nicioli Junior, R. B.; Mattos, C.

profissional dos agentes que são chamados a obedecer a essas ordens e, portanto, a utilizar dispositivos pedagógicos encarregados de facilitar sua aplicação, a saber, os professores primários e os demais professores. (JULIÁ, 2001, p. 10)

O autor ainda propõe que, para esse tipo de abordagem, a história das disciplinas preenche essa lacuna a partir de uma ampliação das fontes tradicionais. Dessa forma, não se pretendem eliminar as variáveis externalistas (políticas, econômicas e sociais), mas aproximálas das normas e práticas internas da escola. A história das disciplinas, discutida por Chervel (1990), mostra que a escola tem a capacidade de produzir uma cultura específica. A escola não realiza uma simples vulgarização do saber erudito, ela elabora métodos e conhecimentos específicos cujos efeitos refletem sobre a sociedade e a cultura. Possuem, portanto, uma cultura escolar que não se estrutura pela ciência erudita, mas para uma necessidade da sociedade.

Desde que se compreenda em toda a sua amplitude a noção de disciplina, desde que se reconheça que uma disciplina escolar comporta não somente as práticas docentes de aula, mas também as grandes finalidades que presidiram sua constituição e os fenômenos de aculturação de massa que ela determina, então a história das disciplinas escolares podem desempenhar um papel importante não somente na história da educação mas também na história cultural. Se se pode atribuir um papel "estruturante" à função educativa da escola na história do ensino, é devido a uma propriedade das disciplinas escolares. (CHERVEL 1990, p. 184)

Nesse sentido, o pesquisador deve estar atento às inovações, e os diferentes registros devem ser analisados de diversas formas, sejam eles de diferentes níveis hierárquicos, como, por exemplo: documentos oficiais, livros, planos de ensino, provas, materiais didáticos em geral etc.

Outro constituinte importante do sistema escolar e que deve ser considerado na análise de uma cultura escolar é o professor. Sua formação também deve ser levada em consideração, uma vez que delimita o enfoque das práticas escolares. Isto remete novamente à história das disciplinas escolares, pois ilustra que as "adaptações" dos professores ao meio escolar específico não são reflexos de uma ciência de referência, mas um produto específico da escola, que, por sua vez, numa causalidade circular, é produto desse professor. Além disso, temos de levar em consideração a interação dos elementos que compõem um nível hierárquico, e uma forma de explorar esses conteúdos é por meio dos livros didáticos, porém, vale destacar novamente que "o manual escolar não é nada sem o uso que dele for realmente feito, tanto pelo aluno como pelo professor" (JULIÁ 2001, p. 34). Dessa forma, o conteúdo existente, como ele é trabalhado em sala de aula e a avaliação parecem estar no coração da "caixa-preta" das práticas de ensino. Seu registro histórico pode apresentar uma historicidade das modalidades de relacionamento entre professor e aluno com o que é ensinado (JULIÁ, 2001; CHERVEL, 1990).

Definidos os caminhos a serem seguidos em uma pesquisa histórica sobre o ensino de Física, devemos definir onde realizá-lo. Para isso, devemos explorar instituições que tive- 
História e memória do ensino de física no Brasil: ...

ram importante papel no ensino científico brasileiro. Uma delas é a Faculdade de Medicina de São Paulo, criada em 1913. Até o ano de 1943, a Faculdade teve a responsabilidade de preparar e capacitar seus alunos com disciplinas de ciências (Física, Química e Biologia) para cursarem disciplinas de nível Superior nos anos seguintes do curso. Buscando resgatar a história e memória do ensino de Física nessa instituição, analisamos vários tipos de documentos encontrados em seu arquivo permanente, tentando responder, além das questões inicialmente propostas, às seguintes perguntas: Quais as principais práticas pedagógicas usadas na época? Quais os tipos de conteúdos estudados, e sofreram modificações? Qual a formação de seus professores de Física? Quais os livros didáticos utilizados?

\section{A pesquisa}

O levantamento de dados foi feito na atual Faculdade de Medicina da Universidade de São Paulo. Foram analisados regimentos, regulamentos, memórias históricas, bem como documentos didáticos como notas de aula e provas arquivadas desde o ano de 1913, quando se iniciou o curso de Física, até 1943, último ano em que foram encontrados documentos referentes ao ensino de Física na Faculdade. Sobre a estrutura educacional encontramos informações no museu histórico localizado na própria Faculdade. Nele obtivemos autorização de acesso a livros e regulamentos, muito bem guardados pela bibliotecária.

No arquivo permanente da Faculdade de Medicina, encontramos os prontuários de quase todos os alunos da faculdade desde sua fundação, já que um incêndio, no ano de 1999, destruiu uma pequena parte do acervo. Nesses prontuários encontram-se desde fotos dos alunos, históricos escolares e recibos, até as provas realizadas pelos alunos e corrigidas pelos professores.

Por meio desses documentos, pudemos resgatar: importantes dados sobre o cotidiano escolar dos alunos, bem como informações sobre a estrutura curricular ao longo dos anos, os conteúdos estudados, os livros didáticos e os critérios para a avaliação e correção das provas. Foram averiguados, aproximadamente, quinhentos prontuários, dos quais foram fotografadas 171 provas, já que muitas provas eram repetidas. Elencamos, também, na bibliografia, um total de nove livros de cinco autores diferentes citados em algumas provas realizadas por candidatos ao curso pré-medico ${ }^{5}$ de 1934.

\section{A Faculdade de Medicina de São Paulo}

\section{Análise político-organizacional}

A Faculdade de Medicina de São Paulo foi resultado da necessidade e do reconhecimento social que já se instalara em São Paulo no século XX. Com um desenvolvimento econô-

\footnotetext{
${ }^{5}$ Curso de nível secundário exigido para ingressar no ensino superior.
} 
Nicioli Junior, R. B.; Mattos, C.

mico e político digno das cidades grandes, São Paulo sofria com a falta de médicos. A realidade educacional do Brasil naquela época era bem diferente da dos dias de hoje, uma vez que a escola foi exclusivamente criada pelas e para as elites burguesas (BITTENCOURT, 2003). Portanto, o candidato a qualquer curso superior pertencia a uma classe social privilegiada.

No que diz respeito ao ensino de Física no secundário, a disciplina se tornou obrigatória para ingresso no Ensino Superior somente no final do século XIX e, mesmo assim, tardou a ganhar destaque no ensino secundário brasileiro devido ao forte tradicionalismo do ensino humanístico-literário que havia na época. No início do século XX, São Paulo e Rio de Janeiro eram os "polos científicos" do Brasil, uma vez que formavam engenheiros e médicos. Para isso, esses cursos necessitavam iniciar o aluno nas disciplinas científicas, justificando a disciplina Física de nível secundário estar no primeiro ano do Ensino Superior (NICIOLI JUNIOR; MATTOS, 2008b). Por isso, essas instituições foram muito importantes para o ensino brasileiro, já que foram as pioneiras do ensino científico no Brasil. Em 1913, no primeiro ano de funcionamento da Faculdade de Medicina de São Paulo, as únicas três cadeiras que compunham o quadro curricular eram: Física Médica, Química Médica e História Natural Médica (Biologia) $)^{6}$, que juntas denominavam o "ano único" (LEIS..., 1913).

Apesar disso, mesmo com sua criação em 1912, a Faculdade teve dificuldades para o estabelecimento de sua continuidade, pois não dispunha de um prédio para ministrar as aulas. A primeira sede, provisória, da Faculdade "foi instalada na Escola de Comércio Álvares Penteado, cedida gentilmente pela sua diretoria. Nela tiveram lugar as primeiras inscrições para o exame de admissão que ficaram abertas de 14 a 21 de fevereiro de 1913" (FARINA, 1972, p. 20). Os exames eram aplicados por professores do Ginásio do Estado da Capital. A aula inaugural foi realizada em 2 de abril de 1913, e foi proferida, no salão da escola Politécnica, pelo professor Edmundo Xavier, professor da cadeira de Física e Química Médica.

No primeiro ano do curso, havia cento e oitenta alunos, dos quais setenta terminaram o ano e somente 34 foram aprovados ${ }^{7}$. Eram realizadas quatro provas parciais durante o período letivo "cuja média era somada à nota do exame oral para, por meio dos coeficientes ponderais, ser calculada nova média final de aprovação e reprovação" (FARINA, 1972, p. 23). Nesse primeiro "ano único", houve um acontecimento que nos chamou a atenção quanto ao cotidiano escolar daquela época, e que justifica, em parte, o pequeno número de setenta alunos (dos cento e oitenta matriculados) que chegaram ao final do ano. Já na primeira prova do primeiro ano, quase todos os alunos tiveram notas insuficientes, provocando uma grande insatisfação por parte dos alunos. Para manifestar sua indignação, os alunos vaiaram os professores. "Queixavam-se unanimemente do julgamento das provas, ninguém acusa ninguém e todos condenavam o insólito procedimento" (FARINA, 1972, p. 28). O então diretor repreendeu os alunos prometendo que, em caso de reincidência, medidas drásticas seriam tomadas. Infelizmente, o fato voltou a acontecer, fazendo com que 52 alunos fossem suspensos por um ano e, evidentemente, perdessem o ano letivo (FARINA, 1972).

\footnotetext{
${ }^{6}$ No ano seguinte, a História Natural é especificada com "desenvolvimento especial para parasitologia". (LEIS...,1913, p. 13).

${ }^{7}$ Em 1914, houve 101 alunos no preliminar; em 1915, 62 alunos; em 1916, 30 alunos; em 1917, 52 alunos, e, em 1918, sessenta alunos.
} 
História e memória do ensino de física no Brasil: ...

Analisando os documentos históricos, vimos que o professor Edmundo Xavier, além de ocupar a cadeira de Física e Química Médica, foi o responsável pela implantação desse curso na Faculdade, viajando à Europa para estudar o ensino teórico e as práticas laboratoriais em alguns países. Com uma grande experiência na área, Xavier foi professor de Física e Química no antigo curso anexo da Faculdade de Direito de São Francisco, "o curso dos bichos" como era conhecido, por abrigar calouros da velha Academia. Xavier lecionou por muitos anos no ginásio do Estado, de onde saiu para a cátedra de Física na Faculdade de Medicina. Além disso, professor Xavier tinha uma formação específica, dedicando-se

[...] além do magistério, à aplicação de eletricidade na terapêutica e teve seu estabelecimento sempre procurado por pacientes. Depois do advento do raio $\mathrm{X}$, foi um dos primeiros a introduzi-lo em São Paulo, não só para obra diagnóstica como para tratamento. (FARINA, 1972, p. 152)

Além disso, Farina (1972), ao comentar alguns acontecimentos importantes na área de Física Médica, destaca a especialização, no exterior, dos professores em medicina e, também, uma exigência da Faculdade em preencher o quadro de professores preferencialmente com médicos, o que justifica as aulas e provas com conteúdos muito específicos 8 .

Quanto às aulas de Xavier, as mesmas estavam de acordo com o caderno de Leis e Regulamentos de 1913, nos quais era exigida, dos professores, a exposição do conteúdo na forma de conferência, com uma hora de duração e com uma preleção de quarenta minutos. Farina (1972) resgata as difíceis aulas e provas do professor Xavier, com o depoimento de Jaime Candelária, aluno à época:

As aulas de Xavier eram do tipo conferência. Era fluente, falava depressa não podíamos acompanhá-lo em seu raciocínio [...] ademais, enquanto falava ia enchendo o quadro negro com complicadas fórmulas de Química [...] estavam as coisas nesse pé, quando veio em nosso socorro um moço chamado Ericson. Habilíssimo taquígrafo do Congresso, Ericson não perdia uma palavra nem fórmula das exposições do mestre [...]. No dia da prova estávamos mergulhados em um profundo silêncio, quando o professor Xavier escreveu no quadro negro as seguintes questões: Qual a reação a que o ácido amino succínico pode dar lugar com o ácido azotoso?; Qual a reação a que pode dar lugar o ácido amino succínico quando aquecido com o álcali? Qual a substância que por esse meio pode ser preparada? Estabelecer as analogias existentes

\footnotetext{
${ }^{8}$ Por exemplo, algumas especializações foram realizadas por professores da cadeira de Física médica: em 1918, o Dr. Raphael Penteado de Barros estava em comissão, como membro da Missão médica Paulista, na Conflagração Européia. Em 1920, o Dr. Oswaldo Portugal estava em comissão, para estudar o problema do radium na Europa e Estados Unidos. Em 1924, o Dr. Raphael Penteado de Barros estava em comissão nos Estados Unidos, para aperfeiçoar os seus estudos de Radiologia.
} 
Nicioli Junior, R. B.; Mattos, C.

entre a reação que nos dá na uréia pelo aquecimento do carbonato de amenia e que é empregado na preparação da oxamida.

Parece-me que a turma decepcionada ao extremo estava à beira de um colapso. E não era por menos, pois que em aulas práticas nunca fizeram experiências como aquelas sobre os quais teríamos de dizer nas provas. (FARINA, 1972, p. 32-34)

Esse depoimento mostra como os alunos ficaram indignados com as primeiras avaliações ocorridas naquele primeiro ano da Faculdade, e que havia uma distância entre o que era trabalhado na sala de aula e o exigido pelo professor. Identificamos esse descompasso através das provas dos alunos realizadas nesse ano, no qual muitas avaliações de Física apresentavam notas baixas. O conteúdo das provas era definido por pontos sorteados, dos quais cada um apresentava um grupo de conteúdos que deveriam ser descritos pelo aluno. Muitas dessas provas com notas insatisfatórias tinham escrito, na folha de avaliação, "Fora do Ponto", anulando toda a resposta feita pelo aluno que não tratava do assunto especificado. Outra observação é que, pela citação acima, podemos perceber que o conteúdo da prova de Química era qualitativo, por meio de dissertações. Em nossa pesquisa, encontramos inúmeras provas de Física, desde 1913, nas quais a forma de avaliação também era qualitativa. Mais adiante, faremos uma discussão mais elaborada dessas provas.

Foi somente em 1926, "em virtude do estatuído na Reforma Pedro Dias a cadeira de Física Médica passa a denominar-se simplesmente Física" (NOTAS..., 1926, p. 43). Essa lei é um reflexo da Reforma Rocha Vaz de 1925, que divide a Física e a Química em duas cadeiras distintas (MACHADO, 2002). Apesar disso, em nossa análise das provas, o termo "Física" foi citado somente nos exames de admissão, sendo a disciplina do primeiro ano do curso chamada de "Física Médica" até o ano de 1932". Entre os anos de 1926 e 1933, foram exigidos, para ingresso na faculdade, exames de admissão de Física, Química e História Natural (Biologia).

Em 1931, depois de parcerias para a construção do prédio, foi inaugurada a sede localizada na avenida Dr. Arnaldo, em frente ao cemitério do Araçá. Nesse mesmo ano, tivemos a Reforma Francisco Campos, de 18 de abril de 1931 (decreto no 19890), dando ao exame de admissão um caráter nacional, ou seja, em todo o país começou a ocorrer uma seleção para ingresso no curso secundário (MACHADO, 2002). Além disso, a Reforma de 1931 dividiu o curso secundário em fundamental e complementar.

Concluído o curso fundamental os alunos podiam optar por uma das três alternativas oferecidas no curso complementar de acordo com a carreira pretendida: $1^{\circ}$ curso jurídico; $2^{\circ}$ curso de medicina, farmácia e odontologia; $3^{\circ}$ curso de engenharia e arquitetura. O curso complementar era na verdade um curso pré-universitário, no sentido de que preparava os alunos para o ensino superior, com disciplinas obrigatórias ligadas às suas diversas áreas. (PILETTI, 1987, p. 62)

\footnotetext{
${ }^{9}$ Isso é explicado devido ao fato de que o curso de Física estava no introdutório superior até 1932, quando é criado o curso complementar.
} 
História e memória do ensino de física no Brasil: ...

No caso da medicina, esse curso complementar se chamava pré-médico. Dessa forma, os conteúdos dos anos introdutórios do curso superior médico foram transferidos para o curso pré-médico, fazendo parte, finalmente, do ensino secundário, sendo os programas "organizados pelos professores do curso pré-médico, os quais, em direto entendimento com a comissão de ensino, estabelecerão a necessária orientação didática e científica, harmonizando o ensino com as disciplinas do curso normal de ciências médicas" (REGULAMENTO..., 1932, p. 54). Isso fez com que fosse abolido o exame de admissão diretamente para o curso superior médico a partir de 1934.

No primeiro ano de implantação houve uma adaptação quanto aos candidatos inscritos,

[...] no presente ano de 1932, os exames vestibulares ao primeiro ano médico serão feitos em conjunto com os exames de admissão ao curso pré-médico [...] os candidatos classificados serão divididos em duas séries, cabendo aos que obtiveram médias elevadas o direito de matricular no primeiro ano do curso médico e reservando-se aos restantes o direito de classificar entre os candidatos no curso pré-médico. (REGULAMENTO..., 1932, p. 56)

Inicialmente, o curso pré-médico teve a duração de um ano, "diferenciando da lei federal [Reforma Campos], o qual propunha um curso de dois anos" (SILVA, 2006, p. 83). Segundo o artigo 371 do Regulamento

[...] oportunamente, o regime efetivo do decreto federal $\mathrm{n}^{\circ} 19890 \mathrm{de}$ 14 de abril de 1931, o ensino do curso pré-médico será reorganizado e desdobrado em dois anos letivos, de modo a corresponder aos objetivos do curso "complementar" de instrução secundária ou pré-universitária prevista pelo referido decreto. (REGULAMENTO..., 1932, p. 57)

No dia 25 de janeiro de 1934, a Faculdade de Medicina passou a integrar a Universidade de São Paulo pelo decreto 6.283, e, a partir dessa data, a Faculdade recebeu a denominação que mantém até os dias de hoje. Além disso, o curso complementar passa a ser denominado de Colégio Universitário e o curso pré-médico passa a ter duração de dois anos (SILVA, 2006), sendo a Física ensinada nas duas séries. Entre os anos de 1934 e 1941, para o ingresso no colégio universitário, eram exigidos exames de admissão de Física, Química, Zoologia e Botânica. O exame de admissão ao superior foi implantado a partir de 1938, sendo exigido Física, Química, História Natural, Sociologia, Inglês e Desenho (Quadro 1).

\section{Análise pedagógica-organizacional}

Analisando as provas, pudemos observar que, nos primeiros anos do curso, eram realizadas três provas anuais. Em alguns destes anos, foram encontrados mais de três tipos de prova, porém em menor número, nos levando a acreditar que o excedente era aplicado aos alunos faltosos ou em recuperação. A partir de 1915, começaram a ser realizadas quatro pro- 
Nicioli Junior, R. B.; Mattos, C.

vas anuais. Em alguns prontuários dos alunos, existem provas realizadas em janeiro, o que presumimos serem provas de recuperação para alunos que não atingiram a média no ano anterior. Somente em 1926 começaram a ser realizados exames de admissão.

Quadro 1. Organização curricular do curso de Física da Faculdade de Medicina

\begin{tabular}{|c|c|c|c|c|c|}
\hline Ano & Curso exigido & Disciplina & $\begin{array}{c}\text { Admissão } \\
\text { (ensino superior) }\end{array}$ & Curso & Disciplina \\
\hline $\begin{array}{c}1913 \text { até } \\
1925\end{array}$ & Ginasial & $\begin{array}{l}\text { Ciências } \\
\text { Naturais }\end{array}$ & Somente certificado ginasial & $\begin{array}{l}\text { Preliminar } \\
\text { (superior) }\end{array}$ & Física Médica \\
\hline $\begin{array}{c}1926 \text { até } \\
1931\end{array}$ & Ginasial & $\begin{array}{l}\text { Ciências } \\
\text { naturais }\end{array}$ & $\begin{array}{l}\text { Provas de Física, Química e } \\
\text { História Natural (Biologia) }\end{array}$ & $\begin{array}{l}\text { Preliminar } \\
\text { (superior) }\end{array}$ & Física Médica \\
\hline $\begin{array}{c}1932 \mathrm{e} \\
1933\end{array}$ & $\begin{array}{l}\text { Fundamental + } \\
\text { Complementar }\end{array}$ & $\begin{array}{l}\text { Física } \\
\text { Pré-Médico } \\
1^{\circ} \text { ano }\end{array}$ & $\begin{array}{l}\text { Provas de Física, Química e } \\
\text { História Natural (Biologia) }\end{array}$ & Medicina & $\begin{array}{l}\text { Anatomia, } \\
\text { fisiologia etc. }\end{array}$ \\
\hline $\begin{array}{c}1934 \text { até } \\
1943\end{array}$ & $\begin{array}{l}\text { Fundamental + Provas de } \\
\text { Admissão para o } \\
\text { Complementar (Física, } \\
\text { Química, Zoologia e } \\
\text { Botânica) + } \\
\text { Complementar }\end{array}$ & $\begin{array}{l}\text { Física } \\
\text { Pré-Médico } \\
1^{\circ} \text { e } 2^{\circ} \text { anos }\end{array}$ & $\begin{array}{l}\text { De } 1934 \text { até } 1937 \text { - somente } \\
\text { aprovação no pré-medico } \\
\text { De } 1938 \text { até } 1943 \text { - Provas } \\
\text { de Física, Química, História, } \\
\text { Sociologia, Inglês e Desenho } \\
\text { (superior) }\end{array}$ & Medicina & $\begin{array}{l}\text { Anatomia, } \\
\text { fisiologia etc. }\end{array}$ \\
\hline
\end{tabular}

Fonte: Elaborado pelos autores.

No ano de 1932, de acordo com o Regulamento de 1932 citado anteriormente, o curso pré-médico tinha um ano letivo, sendo a Física uma das disciplinas. Além de uma prova de admissão para ingressar no curso pré-médico, o aluno realizava duas provas anuais. A partir do ano de 1934, o curso pré-médico, chamado de Colégio Universitário, passa a ter dois anos, sendo a Física ensinada em ambos. Em uma das provas de admissão do ano de 1934, notamos um fato curioso e, ao mesmo tempo, importante para nossa pesquisa. Alguns candidatos citaram livros didáticos como bibliografia consultada. Provavelmente, durante a prova, o responsável pela sala ou algum professor pediu para que os alunos citassem os livros nos quais haviam estudado, pois somente nesse ano houve essas citações. Foram citados os autores: Adolph Ganot (1872, 1923), Francisco Ribeiro Nobre (1896, 1911), Joseph Langlebert (1892, 1934), Raul Romano (1928) e Pádua Dias (1920, 1933), todos autores de livros consagrados na época (NICIOLI JUNIOR; MATTOS, 2007b), mostrando a grande importância que este material tinha como um dos principais apoios pedagógicos.

Michalang (1993), ex-professor da Faculdade de Medicina da Universidade de São Paulo, ao recordar sobre seus estudos na adolescência, evidencia que, em alguns casos, a adoção dos livros era imposição de seus autores. Por exemplo, o então diretor do Ginásio Independência, "chamado Raul Romano, era muito rigoroso com a disciplina e um tanto convencido de sua sabedoria. Certa vez, ao substituir o professor de Química, colocou o seguinte aviso: Assumo hoje a cadeira de Química. Exijo os livros de minha autoria” (MI- 
História e memória do ensino de física no Brasil: ...

CHALANG, 1993, p. 17). Como os livros dos autores citados apresentam os conteúdos de maneira peculiar, faremos uma breve discussão das principais características adotadas para sua exposição, a fim de compará-los posteriormente com a análise das provas.

\section{Os livros didáticos}

A primeira ênfase na abordagem do conteúdo dos livros tem como característica uma exposição descritiva do conteúdo através de máquinas, experimentos e aparelhos do cotidiano da época, e que classificamos como descritivo-experimental (NICIOLI JUNIOR; MATTOS, 2008a). Essa nova metodologia de apresentação do conteúdo iniciou-se na metade do século XIX, exatamente pelos livros de Ganot (1872), Nobre (1896) e Langlebert (1892). Os livros estrangeiros estavam se adequando à nova visão positivista da ciência e, assim,

[...] o conteúdo deixa de oferecer os elementos filosóficos e históricos que traduzem os embates em torno dos conceitos e teorias, e passam a analisar equipamentos fotográficos, fonógrafos, telégrafos, telefones, microfones, instrumentos de meteorologia e climatologia, bombas hidráulicas, motores, geradores etc. (WUO, 2003, p. 317)

Acreditamos ser o autor Adolph Ganot o principal idealizador dessa nova proposta, pois a primeira edição de seu livro é a mais antiga de todos os livros citados.

Ganot era doutor em ciências físicas, diretor de estudos do laboratório de pesquisas físicas da escola prática de Hautes Études e bacharel em matemática e filosofia, além de ser professor de matemática e ciências físicas e naturais. O livro de Ganot Traité élémentaire de physique foi publicado em 1851 e, três anos mais tarde, foi ampliado, passando a incluir conceitos de meteorologia. O novo texto, agora intitulado Traité élémentaire de physique experimentale et appliqueé et de météorologie (1851), teve dezoito reedições. A $17^{a}$ edição foi muito importante, visto que inclui experiências práticas e informações sobre os materiais e instrumentos necessários para o desenvolvimento das mesmas (LORENZ, 1986). Além disso, esse livro foi fortemente adotado em outros países. No Uruguai, Parella (2005, p. 7) comenta que "em relação aos textos de Adolphe Ganot, é muito provável que os estudantes da época estudaram o livro em seu idioma original".

Sobre a grandiosidade da obra, Parella (2005, p. 7) comenta:

O livro de Ganot, mais conhecido como “Traité Élémentaire de Physique”, em 1887 tinha na França várias edições. Esse livro é um tratado de Física de mais de mil páginas. Encontra-se um exemplar dessa edição em francês de 1887 na biblioteca do Liceu de San Carlos. É uma obra monumental, pela extensão e o conteúdo. Os temas gerais que trata são: Noções preliminares, gravidade, hidrostática, estática dos gases, calórico, magnetismo, eletricidade e meteorologia. Cada um dos temas é estudado com maior detalhe. Inclui apêndices com valores de constantes físicas, conversões de unidades e um especial com problemas e perguntas (com soluções). Alguns desses problemas foram ex- 
Nicioli Junior, R. B.; Mattos, C.

traídos de provas reais propostas. As descrições e explicações de funcionamento dos aparatos e instrumentos de laboratório são realizadas em detalhe incluem também sugestões para o uso desses aparatos de laboratório. É um texto que se projeta o laboratório, fazendo uma forte ligação às observações experimentais sem deixar de fazer menção às aplicações cotidianas da Física. As ilustrações (em sua maioria desenhos e na edição de 1924 também se incluem fotografias) somam mais de 1000 e são realizadas com um grande detalhe. As explicações incluem algumas poucas definições apelando para cálculo diferencial, não aparecem excessivas demonstrações teóricas e em sua maioria se explica com elementos de geometria. Ganot diferencia no texto as idéias centrais necessárias para os cursos das idéias auxiliares utilizando dois tipos de letra.

Em outra citação sobre Ganot, agora em tradução americana, o tradutor comenta:

O Elementos de Física, do qual este presente trabalho é uma tradução, adquiriu alta reputação na introdução das Ciências Físicas. Na França passou para a extensa nona edição em poucos anos e tem sido traduzido na Alemanha e Espanha. Esta reputação é muito provável deve-se à clareza e concisão com as principais leis físicas e explicações dos fenômenos, sistemáticos arranjos e excelentes ilustrações. (ATKINSON apud GANOT, 1872, p. 1 tradução nossa)

Gonzáles (2000), ainda comentando sobre a grande difusão de Ganot na Espanha, salienta que o primeiro livro foi em francês, sendo a primeira edição em castelhano produzida em 1853, chegando a sua $18^{a}$ edição em 1923. Sobre sua importância, Gonzáles (2000, p. 76) ressalta que

[...] se não o primeiro, é um dos iniciadores na intercalação de gravuras no texto, no acréscimo de exercícios resolvidos no final, salvo nas primeiras edições. Sem segurança, mas apoiado em referências e impressões de outros colegas estrangeiros, talvez seja este livro que mais tenha influenciado na organização dos ensinos de Física na Europa e América, desde que tais ensinos tiveram caráter curricular nos estudos secundários, profissionais e inclusos nos primeiros anos das Faculdades de Ciências.

Langlebert (1892) e Nobre (1896) também tiveram grande aceitação na Europa e Américas. Durante o levantamento desses livros, foram encontradas traduções no idioma português e espanhol (México). Langlebert era professor de Ciências Physicas e Naturais, doutor em Medicina e "Official da Academia", enquanto Nobre era: Bacharel em Matemática e Filosofia pela Universidade de Coimbra, Professor do Liceu Central do Dr. José Falcão, em Coimbra, Professor do antigo Liceu Central de Beja, do Liceu Central do Porto, do Liceu Central de 
História e memória do ensino de física no Brasil: ...

Alves Martins em Vizeu, além de sócio efetivo do Instituto de Coimbra, da Sociedade de Geografia de Lisboa etc. A abordagem do livro desses autores segue o mesmo estilo de Ganot.

A segunda ênfase abordada por esses livros é a demonstrativo-experimental. É na passagem do século XIX para o século XX que consideramos essa mudança de abordagem (NICIOLI JUNIOR; MATTOS, 2008a). Entendemos isso como uma descrição matemática e exemplos hipotéticos mais detalhados. Vale ressaltar que os experimentos não foram descartados dos livros didáticos, ou seja, são acrescidas deduções algébricas que, antes, não existiam ou estavam em letras menores, como um aprofundamento do conteúdo. Além disso, começam a aparecer exercícios quantitativos para serem resolvidos. Mais uma vez, é nos livros de Ganot que são encontrados os primeiros exercícios (edições mais antigas) e, depois, incorporados nos livros de Langlebert e Nobre.

Os livros de Antonio de Pádua Dias ${ }^{10}$ e Raul Romano ${ }^{11}$ começam a aparecer no currículo nacional a partir de 1920, e apresentam algumas inovações. Ao mesmo tempo, os livros europeus começam a ser menos usados, desaparecendo por completo no início da década de 1930. Dias e Romano realizam adaptações em seus livros, as quais foram justificadas por Romano (1928, p. 1) da seguinte forma:

[...] não pertencemos ao número d'aquelles que pensam dever o ensino ser exclusivamente prático, e por isso mesmo todas as vezes que na exposição do assumpto não foi possível fazer rápidas divulgações philosophicas e mathematicas, fizemo-las, mas procurando manter sempre um justo equilíbrio entre a vantagem de habituar os alumnos ao raciocínio [...] procuramos expor o assumpto com a máxima clareza, mas sem prolixidade, e por isso mesmo achamos de boa norma não perdermos muito tempo com enfadonhas descripções de aparelhos que, não sendo vistos no original, de nada valem.

Podemos identificar nessa nova abordagem, em ambos os livros, um resumo das descrições dos experimentos, mas não um desaparecimento completo, e um aumento das demonstrações algébricas. Um destaque importante do livro de Romano (1928) é a inclusão dos exercícios nos livros. É muito importante ressaltar que a metodologia de aplicação dos exercícios nos livros brasileiros foi iniciada nessa época, porém não como nos livros franceses onde isso era realizado como apêndice, mas diretamente no conteúdo. Essa nova proposta altera o conteúdo dos livros didáticos de Física para sempre. O que vemos a partir daqui é a introdução dos exercícios no conteúdo dos livros, na função de exemplos e na fundamentação do conteúdo. Como exemplo, citamos abaixo um exercício do livro de Romano (1928, p. 21):

\footnotetext{
${ }^{10}$ Consta na capa de seu livro: "Formado em engenharia civil e professor catedrático de Física do Estado de São Paulo" (DIAS, 1933).

${ }^{11}$ Consta na capa de seu livro: "Romano teve como formação engenharia química, foi diretor e professor de Física e Química em diversos colégios” (ROMANO, 1928).
} 
Nicioli Junior, R. B.; Mattos, C.

Exemplo numérico - Um cyclista, cuja massa total é de 90 Krg lançase numa pista circular de $25 \mathrm{~m}$ de raio, com velocidade de 15 metros por segundo.

Qual é a força centrífuga?

$\mathrm{M}=90.000=9 \times 10^{4}$

$\mathrm{V}=15 \times 10^{2}$

$\mathrm{R}=25 \times 10^{2}$

Logo:

$$
\mathrm{F}=\mathrm{mv}^{2} / \mathrm{R}=\frac{9 \times 10^{4} \times\left(15 \times 10^{2}\right)^{2} \cdots}{25 \times 10^{2}}
$$

Apesar de ser mais sucinto na descrição dos experimentos, como afirma Romano (1928), o conteúdo do livro se assemelha muito aos dos livros didáticos europeus. A mesma semelhança é observada no livro de Dias $(1920,1933)$, como podemos ver na Figura 1.

Figura 1. Semelhanças entre: (a) a $31^{\mathrm{a}}$ edição do Traité élémentaire de physique de Ganot (1923, p. 47) e (b) Curso elementar de Física, de Dias (1933, p. 25)

(a)

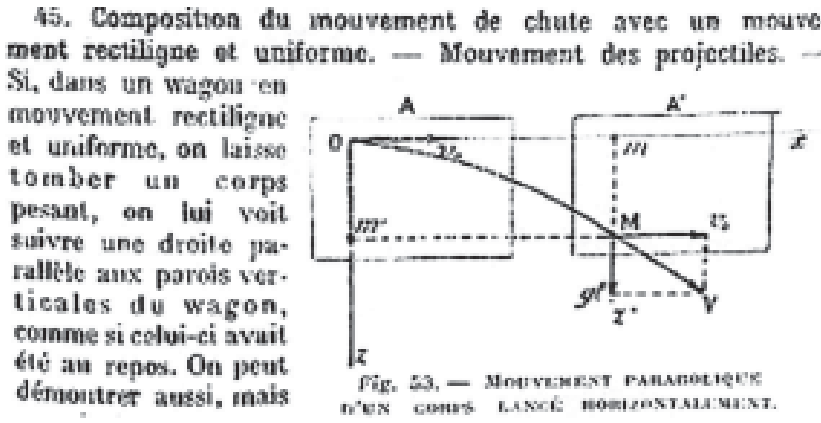

(b)

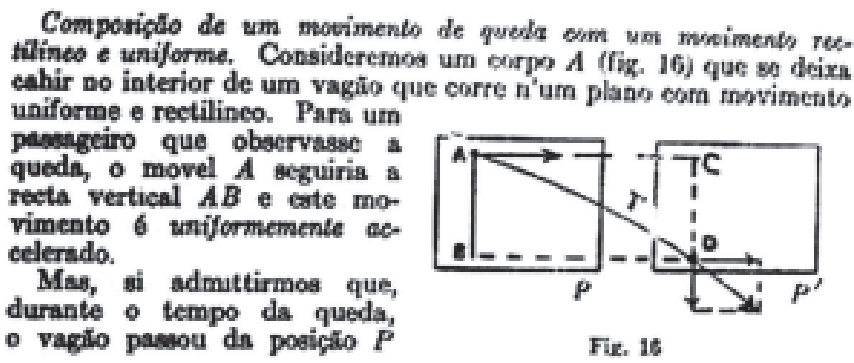

Fontes: Ganot (1923) e Dias (1933). 
História e memória do ensino de física no Brasil: ...

\section{O conteúdo das provas}

As provas encontram-se nos prontuários individuais dos alunos, juntamente com os documentos apresentados durante o curso. Muitas provas eram iguais, já que eram realizadas pelos alunos da mesma sala. Em alguns casos, foi difícil identificar essa ordenação, já que as provas não estavam organizadas de acordo com as turmas, sendo nossa tarefa identificá-las por meio das datas e comparação entre conteúdos das provas. Conforme íamos avançando a análise na escala temporal, novas provas surgiam e uma nova organização se estabelecia.

Pela análise dos conteúdos das provas, pudemos perceber três etapas curriculares com características distintas. A primeira com uma abordagem do conteúdo quase que exclusivamente qualitativo e com alguns conteúdos de física médica (1913-1931). A segunda etapa ainda apresenta uma abordagem qualitativa, mas sem a abordagem médica, concentrada em conteúdos de caráter geral (1932-1938). Na última etapa, os conteúdos têm caráter geral, mas destacase a introdução de exercícios quantitativos nas provas (1939-1943).

Com relação às provas de 1913 a 1931, por ser o período mais extenso, é o que apresenta o maior número de provas analisadas, totalizando 94. Destacam-se conteúdos de física ligados a descrições do corpo humano, diferente do que conhecemos atualmente. Em alguns casos, os conteúdos estão mais relacionados com as ciências biológicas, mesmo sendo provas da cadeira de Física da Faculdade. Alguns desses conteúdos são repetidos em provas posteriores, até o ano de 1931, e representam 25\% de todas as provas desse período. Destacamos, a seguir, três grupos de conteúdos frequentes nas provas:

. Imbibição capilar, Capilaridade, Isotonia, Colóides orgânicos: provas de 1913, 1915, 1917, 1918, 1921, 1923, 1925, 1926.

. Osmose: provas de 1921, 1922, 1923, 1925, 1926, 1928.

. Tensão superficial: provas de 1915, 1920, 1921.

Além disso, em algumas provas, os conteúdos ditos tradicionais da Física apresentaram traços de aplicações na área biológica, principalmente ao corpo humano, somando 14,8\% do total. A distribuição geral dos conteúdos das provas está representada no histograma apresentado no Gráfico 1.

Gráfico 1. Distribuição dos conteúdos específicos de Física nas provas da Faculdade de Medicina de São Paulo (1913-1931)

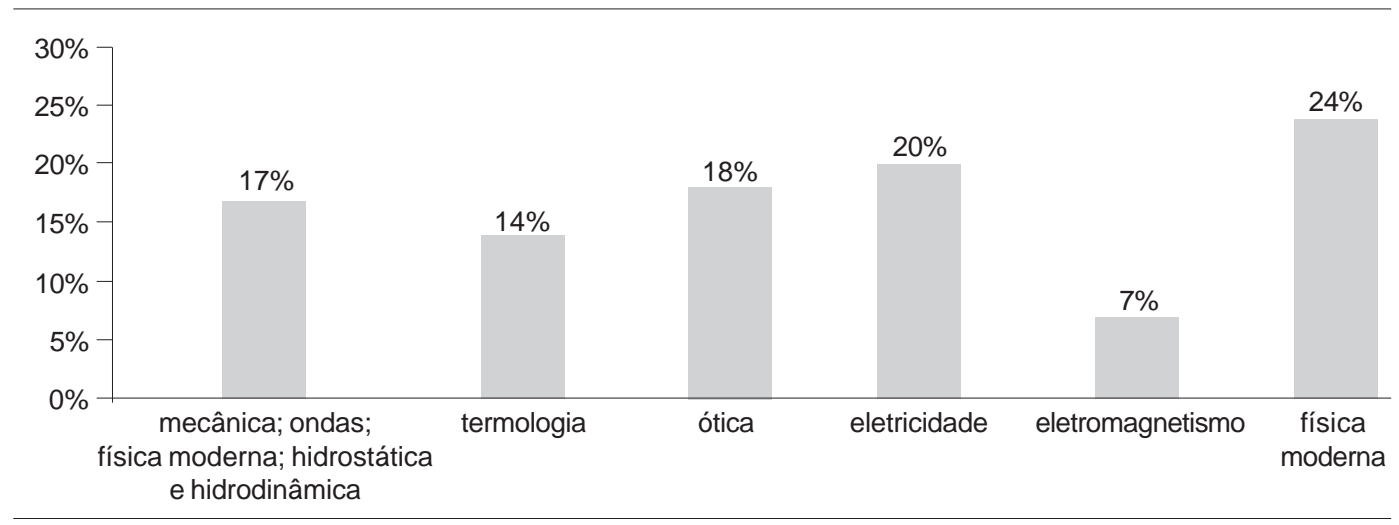

Fonte: Elaborado pelos autores. 
Nicioli Junior, R. B.; Mattos, C.

Podemos observar que, juntamente com o conteúdo médico, a ótica tem uma expressiva abordagem nas provas. Seu conteúdo se assemelha muito ao existente hoje, como equação de Gauss, associação de lentes e, principalmente, ótica da visão, porém tratado na forma dissertativa. Nesse período estudado, apenas cinco provas tiveram exercícios quantitativos com um exercício cada: dois de ótica (lentes e espelhos), um de termologia (calorimetria) e um de eletricidade (lei de Ohm). Todas as outras provas apresentam dissertações sobre os conteúdos apresentados anteriormente. Na Figura 2, apresentamos a imagem de um exemplar de prova de física do ano de 1921, cujo autor versava sobre o tema "tensão superficial".

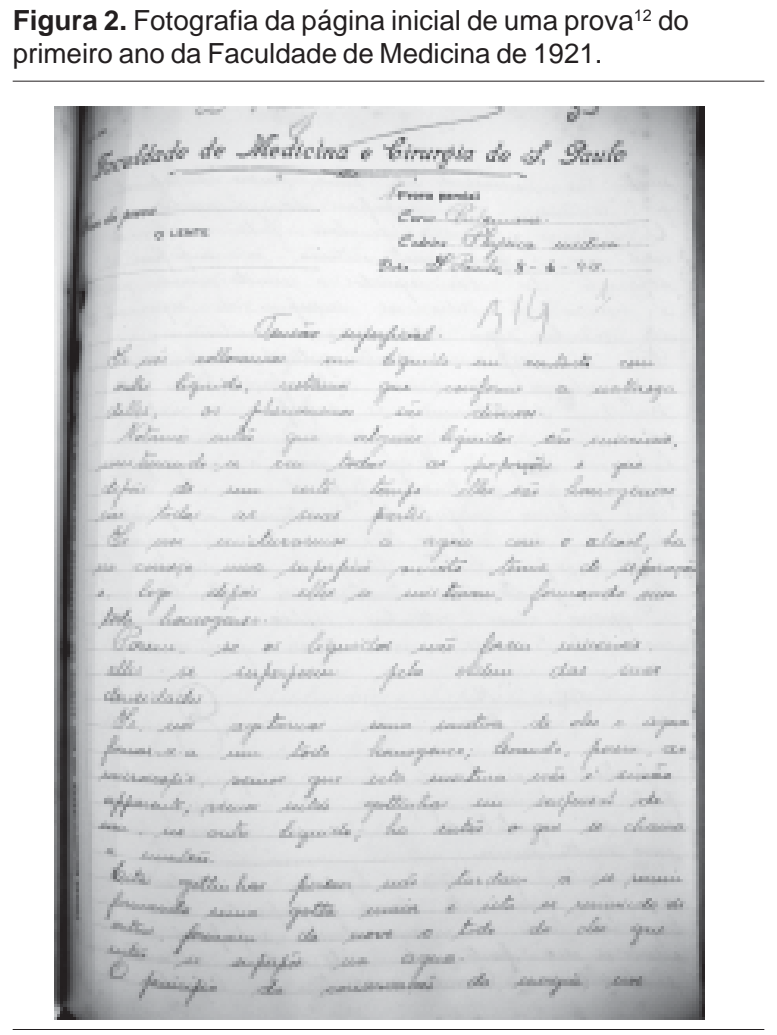

Fonte: Arquivo permanente da Faculdade de Medicina da Universidade de São Paulo.

\footnotetext{
${ }^{12}$ Devido à dificuldade de leitura, transcrevemos o texto da imagem: “Tensão Superficial - Se nós collocamos um liquido, em contato com outro liquido, notamos que conforme a natureza delles, os phenomenos são diversos. Notamos então que alguns liquidos são misciveis, misturando-se em todas as proporções e que depois de um certo tempo elles são homogeneos em todas as suas partes. Se nos misturamos a agua com alcool, ha no começo uma superfície muito tênue de separação e logo depois elles se misturam, formando um todo homogeneo. Porem, se os líquidos não forem miscíveis, elles se superpõem pela ordem das suas densidades. Se, nós agtiamos um amistura de oleo e agua formar-se-a um todo homogeneo; levando, porem, ao microscopio, vemos que esta mistura não é sinão apparente; vemos então gottinhas em suspensão de um, no outro liquido; ha então o que se chama a emulsão. Estas gottinhas porem não tardam a se reunir formando uma gotta maior e isto se reunindo às outras formam de novo um todo de oleo que então se superpõe na agua. O princípio de conservação da energia, nos [...]”
} 
História e memória do ensino de física no Brasil: ...

A diferenciação no conteúdo deve-se, evidentemente, à preparação para as disciplinas médicas dos anos subsequentes, mas, também, aos professores que ministravam as aulas. Como já destacamos, os professores estavam ligados à área médica, quando não eram médicos. Consequentemente, alguns conteúdos estão fortemente ligados às ciências biológicas e os conteúdos ditos tradicionais se apresentam entrelaçados com temas da física médica.

Em 1931, mudanças expressivas ocorrem no conteúdo das provas. Essa transformação ocorre devido à Reforma Francisco Campos de 1931, quando o ensino secundário tornase obrigatório para ingresso no superior em todo o país, já que até então era necessário somente apresentar certificados em algumas disciplinas específicas. Agora, o ensino de Física desvincula-se do ensino superior médico e passa de específico para um caráter geral, sendo modificado, sobretudo, pelos cursos introdutórios existentes na época, como o curso pré-médico.

Entre os anos de 1932 a 1938, foi analisado um total de 35 provas. Destaca-se a ausência dos conceitos de física médica e a predominância das questões qualitativas, apesar de 9 provas apresentarem exercícios quantitativos, somando $24 \%$. Os conteúdos dos exercícios são: mecânica (cálculo do trabalho), eletricidade (lei de ohm e difusão elétrica) e ótica (espelhos e refração da luz). Eram apresentados exercícios na seguinte forma: "Qual o trabalho realizado por um ponto de $5 \mathrm{gr}$. de massa em 11 oscilações completas com um movimento senoidal cuja amplitude é 2 centímetros e cujo período é 12 segundos?”, o qual foi extraído de uma prova de 5 de fevereiro de 1935.

Foram tratados diversos conteúdos nas provas desse período (Gráfico 2). Podemos observar que as parcelas de cada conteúdo na composição das provas começam a adquirir uma estrutura parecida com o que temos atualmente. Isso evidencia a grande importância dos cursos anexos às principais Faculdades do país no remodelamento do ensino de Física brasileiro e, além disso, que sua mudança começa em meados do século XX.

Em épocas posteriores, podemos observar um currículo ainda em construção. No período de 1939 a 1943, analisamos um total de 41 provas. O maior número de provas, em

Gráfico 2. Distribuição dos conteúdos específicos de Física nas provas da Faculdade de Medicina de São Paulo (1932-1938).

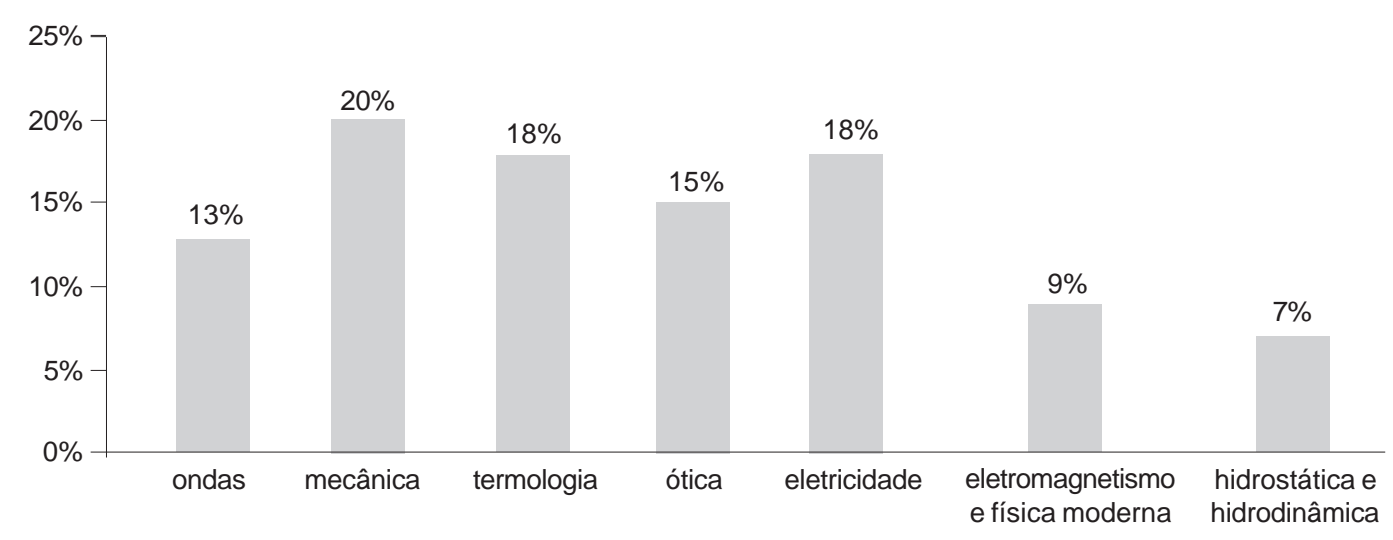

Fonte: Elaborado pelos autores. 
Nicioli Junior, R. B.; Mattos, C.

relação ao período anterior, deve-se ao fato de a Física estar no currículo dos primeiro e segundo anos do colégio universitário anexo à Faculdade. Destacam-se, agora, além das questões qualitativas presentes em todas as provas de todos os anos da Faculdade, as questões quantitativas que, com exceção de uma prova, estão presentes em todas as provas desse período. Durante a análise, é possível notar que houve uma padronização das questões, sendo a primeira questão a composição de uma dissertação; a segunda, uma pergunta cuja resposta deveria ser mais breve, e a última, um exercício quantitativo. Torna-se frequente, também, mais de um conteúdo específico nas provas, como, por exemplo, eletricidade e ótica, fato que era raro nas primeiras provas analisadas. A distribuição dos conteúdos aproxima-se ainda mais do currículo atual, conforme mostra a distribuição de conteúdos específicas apresentadas no Gráfico 3.

Gráfico 3. Distribuição dos conteúdos específicos de Física nas provas da Faculdade de Medicina de São Paulo (1939-1943)

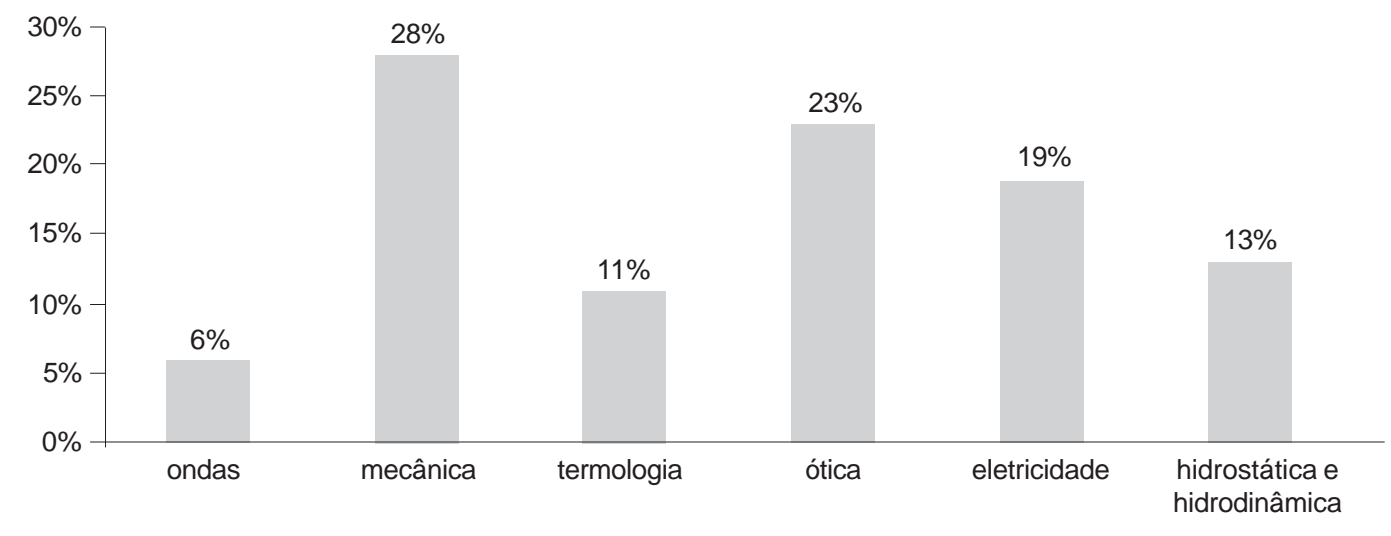

Fonte: Elaborado pelos autores.

Uma avaliação que merece ser destacada são os exames de admissão ao superior, criados em 1938. Essas provas são compostas por exercícios e perguntas de diversos conteúdos e, em termos burocráticos, podem ser comparadas aos vestibulares atuais. Durante o levantamento foi muito difícil encontrar provas que apresentassem todas as questões resolvidas. Por isso, foram levantados 71 exercícios dos 84 possíveis, já que as seis provas apresentavam quatro exercícios e dez questões cada uma. Foram tratados conteúdos de: mecânica (22,5\%), termologia $(25 \%)$, eletricidade $(25 \%)$, ótica $(14 \%)$, ondas $(5,6 \%)$, hidrostática $(2,8 \%)$ e física médica $(4,2 \%)$. Os conteúdos de física médica foram: tensão superficial e capilaridade. 
História e memória do ensino de física no Brasil: ...

\section{Conclusão}

Por meio desse recorte histórico do ensino de Física na Faculdade de Medicina de São Paulo, observamos traços particulares nas práticas escolares realizadas na instituição. Vimos que o curso de Física que, inicialmente, era integrante do currículo superior da Faculdade de Medicina e, posteriormente, torna-se disciplina do curso secundário, parece ter sido essencial no remodelamento curricular de Física, selecionando conteúdos, ou seja, "cristalizando" alguns e esvanecendo outros. Devido à grande importância da instituição, essas mudanças apresentam traços no currículo brasileiro até os dias de hoje.

Segundo Forquin (1992), a memória escolar funciona sempre na base do esquecimento, e o ensinado nas escolas não transmite senão uma ínfima parte da experiência humana acumulada no passado. Dessa forma

[...] o ensino onde o passado não se torna objeto de uma atenção ou de uma tematização explícita, [...] o passado pode permanecer presente, mas sob forma implícita ou latente, incorporado em habitus intelectuais, em modelos de pensamento, em procedimentos operatórios considerados como naturais e evidentes e em tradições pedagógicas. (FORQUIN, 1992, p. 30)

O que destacamos nesse trabalho é o que Forquin (1992) chama de seleção cultural escolar. Nem tudo que constitui uma cultura é importante para a escola e, também, a instituição escolar dispõe de um tempo limitado. Por isso, uma seleção é necessária. Porém, diferentes escolas podem fazer diferentes seleções de conteúdos, e um exemplo claro disso foi o caso da Faculdade de Medicina.

Por meio dos livros didáticos, vimos que há também uma seleção cultural de conteúdos. Por meio de ênfases no conteúdo dos livros didáticos, vimos que eles se modificam ao longo do tempo. Na própria introdução do livro de Romano (1928, p. 3), vimos uma citação do autor destacando "não perder tempo com enfadonhas descrições". Isso não significa um equívoco do autor, mas, sim, que a época mudou e, portanto, as necessidades didáticas também. Temos como hipótese que os livros didáticos dos autores discutidos aqui influenciaram e guiaram, em menor ou maior grau, as mudanças curriculares destacadas nesse trabalho, sendo, inclusive, citados nas provas da Faculdade de Medicina. Porém, como já destacamos, os livros são aproximações do que poderia ter ocorrido na sala de aula.

Sendo assim, a oposição entre currículo escrito (currículos oficiais) e currículo interativo (realizado em sala de aula), já destacada por Goodson (1995), é importante. Se compararmos o currículo do início da Faculdade de Medicina com o currículo oficial, vigente na época, no colégio padrão Pedro II, veremos que suas propostas começam a convergir somente após 1931, quando o conteúdo tem um caráter geral. Segundo Forquin (1992, p. 32), a análise dos

programas curriculares e da seleção que aqueles efetuam [...] deve ser prolongada e completada no próprio local dos estabelecimentos e salas de aula na medida em que existe uma diferença entre aquilo que é pretendido e aquilo que é realmente ensinado. 
Nicioli Junior, R. B.; Mattos, C.

Dessa forma, instituições de ensino adéquam seus currículos de acordo com a necessidade pedagógica da escola e que, às vezes, não vai de encontro aos programas oficiais. Por meio da análise da organização política e educacional da Faculdade de Medicina, é possível identificar que esse tipo de prática já se realiza desde épocas passadas.

Mas a escola não se resume aos programas curriculares e seleção de saberes. Como destacamos no início deste trabalho, Chervel (1990) e Juliá (2001) mostram que a escola não transmite seus conteúdos passivamente, com regras específicas, mas constituem entidades culturais próprias, com criações didáticas originais. Sua análise não deve ser feita somente pela ótica externa, mas, também, pela sua organização interna, uma vez que ambas dialogam entre si, como destaca Juliá (2001). No nosso caso, por meio de uma visão externa, pudemos compreender o enfoque curricular que foi dado ao ensino de Física na Faculdade de Medicina e que foi criado em virtude de uma necessidade social (São Paulo já se destacava pelo forte desenvolvimento político e industrial), sendo a escola a grande responsável pela formação de indivíduos para essa sociedade emergente.

Nessa função, a escola se torna primordial na estrutura social, fazendo com que as disciplinas se encaixem às finalidades impostas, o que lhe confere um papel "estruturante" do processo educativo escolar (CHERVEL, 1990). Compreender as relações entre a disciplina, o curso e as instituições é tentar explicar não só por que o ensino se realizava, mas, também, como se realizava. Aqui mergulhamos nas práticas escolares por meio das relações microscópicas entre o que se estudava e que encontramos materializado nas avaliações do conteúdo de Física. Assim, pudemos expor algumas tradições pedagógicas, procedimentos e condutas sobre o cotidiano escolar da instituição que visavam aprimorar o ensino de Física. Forquin (1992) chama determinados procedimentos pedagógicos de imperativos didáticos, ou seja, métodos que tratam de fazer o aluno aprender e que o conhecimento seja incorporado pelo aluno.

Desta necessidade funcional da didatização decorre um certo número de traços morfológicos e estilísticos característicos dos saberes escolares, por exemplo [...] o lugar concedido às questões e aos exercícios tendo a função de controle ou de reforço". (FORQUIN, 1992, p. 34)

Portanto, as questões e exercícios que observamos nas provas da Faculdade de Medicina são necessidades pedagógicas criadas dentro e para a escola, e que não são constantes e uniformes, uma vez que dependem da sociedade, do público escolar, das matérias. Isso justifica o aparecimento dos exercícios quantitativos entre o período de 1938 e 1943, fato que só é observado analisando-se a "caixa-preta" dos estabelecimentos e das salas de aula, e não, unicamente, a distribuição social, os efeitos sociais das políticas de escolarização ou a evolução das instituições educacionais, como vem sendo ou já foi realizado em muitos trabalhos que analisam o passado do ensino de Física brasileiro.

Além disso, destacamos que o ensino de Física tem sua história em anos anteriores à década de 1940, e que apresenta dados históricos muito importantes sobre a estruturação curricular, sobretudo para compreender as décadas seguintes a esse período até os dias atuais. Isso mostra a necessidade de uma área da "História do Ensino de Física", já que é uma vertente nova e com inúmeras questões a serem respondidas. Apenas um exemplo é o ano de 1931, já que foi muito importante no remanejamento curricular de Física. Podem ser levanta- 
História e memória do ensino de física no Brasil: ...

das indagações como: Quem foram seus responsáveis? Por que e quais seleções culturais escolares foram realizadas? O que era importante na cultura escolar para que esses conteúdos fossem selecionados? Essas são algumas das questões que deixamos sem respostas e, ao mesmo tempo, são sugestões para futuras pesquisas históricas para o ensino de Física. Porém, para que sejam respondidas, devemos investigar o interior das instituições por meio de seus programas curriculares, diários, provas, cadernos e outros documentos do cotidiano escolar que ajudem a traçar o perfil didático e curricular da instituição.

\section{Referências}

ALMEIDA JÚNIOR, J. A. A evolução do ensino de física no Brasil. Revista de Ensino de Física, São Paulo, v. 1, n. 2, p. 45-58, 1979.

. A evolução do ensino de física no Brasil - 2a. parte. Revista de Ensino de Física, São Paulo, v. 2, n. 1, p. 55-73, 1980.

BARRA, V. M.; LORENZ, K. M. Produção de materiais didáticos de ciências no Brasil, período: 1950-1980. Ciência e Cultura, São Paulo, v. 38, n. 12, p. 1970-1983, 1986.

BITTENCOURT, C. M. Disciplinas escolares: história e pesquisa. In: OLIVEIRA, M. A.; RANZI, S. História das disciplinas escolares no Brasil: contribuição para o debate. Bragança Paulista: EDUSF, 2003. p. 9-38.

CARVALHO, A. M. P.; VANNUCCHI, A. O currículo de física: inovações e tendências nos anos noventa. Investigações em Ensino de Ciências, Porto Alegre, v. 1, n. 1, p. 3-19, mar. 1996.

CHERVEL, A. História das disciplinas escolares: reflexões sobre um campo de pesquisa. Teoria \& Educação, Porto Alegre, n. 2. p. 177-229, 1990.

DIAS, P. A. Curso elementar de physica. São Paulo: Vanorden, 1920.

Curso elementar de physica. 3. ed. São Paulo: Salles Oliveira Rocha, 1933.

FARINA, D. C. Memória e tradições da casa de Arnaldo. São Paulo: Faculdade de Medicina de São Paulo, 1972.

FORQUIN, J. C. Saberes escolares, imperativos didáticos e dinâmica social. Teoria $\boldsymbol{\&}$ Educação, Porto Alegre, n. 5, p. 28-49, 1992.

FREITAG, B.; MOTTA, V. R.; COSTA, W. F. O livro didático em questão. São Paulo: Cortez; Campinas: Autores Associados, 1989.

GANOT, A. Traité élémentaire de physique. 31. ed. Paris: Hachette, 1923.

Traité élémentaire de physique experimentale. 15. ed. Paris: Chez L'AuteurÉditeur, 1872.

Natural Philosophy for General Readers and Young People (Cours

Élémentaire de Physique). E. Atkinson (Ed. e Trad.). London: Longmans, Green, and Company, 1872. 
Nicioli Junior, R. B.; Mattos, C.

GASPAR, A. Cinquenta anos de ensino de física: muitos equívocos, alguns acertos e a necessidade de recolocar o professor no centro do processo educacional. Educação: Revista de Estudos da Educação, Maceió, v. 13, n. 21, p. 71-91, dez. 2004.

GONZÁLES, A. M. La física en los manuales escolares: um medio resistente a la renovación (1845-1900). História de la Educación: Revista interuniversitaria, Salamanca, n.19, p. 31-93, 2000.

GOODSON, I. Currículo: teoria e história. Petrópolis: Vozes, 1995.

HAIDAR, M. L. M. O ensino secundário no império brasileiro. São Paulo: EDUSP, 1972.

HAMILTON, D. Sobre as origens dos termos curriculum. Teoria \& Educação, Porto Alegre, n. 6, p. 33-52, 1992.

JULIÁ, D. A cultura escolar como objeto histórico. Revista Brasileira de História da Educação, Campinas, n. 1, p. 9-45. 2001.

KRASILCHIK, M. Inovações no ensino das ciências. In: GARCIA, W. (Org.). Inovação educacional no Brasil: problemas e perspectivas. São Paulo: Cortez; Autores Associados, 1980. p. 164-180.

LANGLEBERT, J. Physique. Paris: Primerie et librairie classiques, 1892.

. Tratado de física elementar. 23. ed. Porto: Aillaud \& Lelo, 1934.

LEIS e regulamentos referentes às Faculdade de Medicina e Cirurgia de São Paulo. São Paulo: Typ. do Diário Official, 1913.

LORENZ, K. M. Os livros didáticos e o ensino de ciências na escola secundária brasileira no século XIX. Ciência e Cultura, São Paulo, v. 3, n. 38, p. 426-435, 1986.

MACHADO, R. C. G. Uma análise de admissão ao secundário (1930-1970): subsídios para a história da educação matemática. 2002. 130 f. Dissertação (Mestrado em Educação Matemática) - Pontíficia Universidade Católica, São Paulo, 2002.

MICHALANG, J. Fatos pitorescos na vida de um médico paulistano. São Paulo: Michalang, 1993.

MOREIRA, M. A. (Comp.). Resumos de trabalhos do Grupo de Ensino do Instituto de Física da UFRGS (1967-1977). Porto Alegre: Universidade Federal do Rio Grande do Sul, 1977. (Publicação interna).

NARDI, R. Memórias da educação em ciências no Brasil: a pesquisa em ensino de física. Investigações em Ensino de Ciências, Porto Alegre, v. 10, n. 1, p. 63-101, 2005.

NICIOLI JUNIOR, R. B.; MATTOS, C. R. As diferentes abordagens do conteúdo de cinemática nos livros didáticos do ensino de ciências brasileiro (1810-1930). Revista Electrónica de Enseñanza de las Ciencias, Vigo, v. 7, p. 199-225, 2008a.

- A disciplina e o conteúdo de cinemática nos livros didáticos de física do Brasil (1801 a 1930). Investigações em Ensino de Ciências, Porto Alegre, v. 13, n. 3 , p. 275-298, 2008b. 
História e memória do ensino de física no Brasil: ...

NICIOLI JUNIOR, R. B.; MATTOS, C. R. A disciplina física no ensino secundário nos anos de 1810 até 1930. In: ENCONTRO NACIONAL DE PESQUISA EM ENSINO DE CIÊNCIAS, 6., 2007, Florianópolis. Atas... Belo Horizonte: ABRAPEC, 2007a. p. 1-12.

$\mathrm{O}$ conteúdo de cinemática nos livros didáticos de 1810 a 1930. 2007. $170 \mathrm{f}$. Dissertação (Mestrado em Ensino de Ciências) - Instituto de Física, Universidade de São Paulo, São Paulo, 2007b.

. Livros didáticos de física (1810-1940). In: SIMPÓSIO INTERNACIONAL DO LIVRO DIDÁTICO, 2007, São Paulo. Atas... São Paulo: Fapesp, 2007c. p. 1231-1245.

NOBRE, F. R. Tratado de physica elementar. Porto: [s. e.], 1896.

. Tratado de física elementar. Porto: Livraria Chard., 1911.

NOTAS para a memória histórica: Faculdade de Medicina de São Paulo. São Paulo: Ed. Limitada, 1926.

OLIVEIRA, J. B. A. A política no livro didático. Campinas: Editora Unicamp; São Paulo: Summus, 1984.

PARELLA, A. Huellas uruguayas en la enseñanza de la física. Educación en Física, Montevideo, v. 7, n. 3, p. 3-33, 2006.

PILETTI, N. Evolução do currículo do curso secundário no Brasil. Revista da Faculdade de Educação, São Paulo, v. 13, n. 2, p. 27-72, 1987.

REGULAMENTO da Faculdade de Medicina de São Paulo. São Paulo: Imprensa Official, 1932.

RODRIGUES, I. G.; HAMBURGER, E. W. O “Grupo de Ensino” do IFUSP: histórico e atividades. São Paulo: Universidade de São Paulo, 1993. (Publicações IFUSP/P-1035).

ROMANO, R. Tratado de física. São Paulo: Melhoramentos, 1928.

SILVA, M. C. O. A matemática do curso complementar da reforma Francisco

Campos. 2006. 211 f. Dissertação (Mestrado em Educação Matemática) - Pontifícia Universidade Católica, São Paulo, 2006.

VILLANI, A. Considerações sobre a pesquisa em ensino de ciência: a interdisciplinaridade. Revista de Ensino de Física, São Paulo, v. 3, n. 3, p. 68-88, 1981.

Considerações sobre a pesquisa em ensino de ciência: II: seu significado, seus problemas e suas perspectivas. Revista de Ensino de Física, São Paulo, v. 4, n. 1, p. $125-150,1982$.

WUO, W. O ensino da física na perspectiva do livro didático. In: OLIVEIRA, M. A. T.; RANZI, S. M. F. (Org.). História das disciplinas escolares no Brasil: contribuições para o debate. Bragança Paulista: EDUSF, p. 299-338, 2003.

Artigo recebido em 03/02/2012. Aceito em 05/08/2012. 